\title{
Princípios pedagógicos do modelo teaching games for understanding: uma visão praxiológica sobre o ensino para compreensão do esporte
}

\section{RESUMO}

O Teaching Games for Understanding, modelo de ensino de esporte para compreensão, apresenta Princípios Pedagógicos específicos para desenvolver, didaticamente, o entendimento da lógica do jogo. No que tange a lógica interna, a Praxiologia Motriz demonstra-se como uma consolidada teoria científica que apresenta conhecimentos para análise dos jogos e dos esportes. Assim, o objetivo desse ensaio é articular os Princípios Pedagógicos do Teaching Games for Understanding (TGfU) com conceitos da Praxiologia Motriz. Por meio de uma pesquisa teórica, articularam-se as características dos Princípios Pedagógicos do modelo TGfU com os conhecimentos da Praxiologia Motriz. A partir desse debate, propôsse um novo Princípio Pedagógico, a Caracterização da Lógica Interna, bem como evidenciou-se a necessidade de o professor dominar os conhecimentos praxiológicos para manipular com sapiência os jogos condicionados que propõe em aula, possibilitando a compreensão da lógica interna.

PALAVRAS-CHAVE: Princípios pedagógicos; Praxiologia motriz; Método de ensino; Pedagogia do esporte; Ensino para compreensão 


\title{
Pedagogical principles of teaching games for understanding model: a praxiological view on sports teaching for understanding
}

\begin{abstract}
The Teaching Games for Understanding, a sports teaching model for understanding, presents specific Pedagogical Principles to develop, didactically, the understanding of game logic. Regarding the internal logic, the Motor Praxiology demonstrates as a consolidated scientific theory that presents knowledge for analysis of games and sports. Thus, the purpose of this essay is to articulate the Teaching Games for Understanding (TGfU) Pedagogical Principles with Motor Praxiology concepts. Through a theoretical research, the TGfU Pedagogical Principles characteristics were articulated with the Motor Praxiology knowledge. From this debate, a new Pedagogical Principle, the Characterization of Internal Logic, was proposed, as well as the necessity of the teacher to master the praxiological knowledge to wisely manipulate the conditioned games that he proposes in class, allowing the internal logic understanding.
\end{abstract}

KEYWORDS: Pedagogical principles; Motor praxiology; Teaching method; Sport pedagogy; Teaching for understanding

\section{Principios pedagógicos del modelo teaching games for understanding: una visión praxiológica} sobre la enseñanza deportiva para la comprensión

\section{RESUMEN}

El Teaching Games for Understanding, un modelo de enseñanza deportiva para la comprensión, presenta principios pedagógicos específicos para desarrollar, didácticamente, la comprensión de la lógica del juego. En cuanto a la lógica interna, la Praxiologia Motriz se demuestra como una teoría científica consolidada que presenta conocimientos para el análisis de juegos y deportes. Por lo tanto, el propósito de este ensayo es articular los Principios Pedagógicos del Teaching Games for Understanding (TGfU) con los conceptos de la Praxiologia Motriz. A través de una investigación teórica, se articularon las características de los Principios pedagógicos de TGfU con el conocimiento de la Praxiologia Motriz. A partir de este debate, se propuso un nuevo Principio pedagógico, la Caracterización de la lógica interna, así como la necesidad del maestro de dominar el conocimiento praxiológico para manipular sabiamente los juegos condicionados que propone en clase, permitiendo la comprensión de la lógica interna.

PALABRAS-CLAVE: Principios pedagógicos; Praxiología motriz; Método de enseñanza; Pedagogía deportiva; Enseñanza para la comprensión 


\section{INTRODUÇÃO}

Os esportes, como fenômenos culturais, manifestam-se nas diferentes esferas sociais, especialmente nos âmbitos educacionais, participativos, de desempenho e de iniciação esportiva (BRASIL, 2015). Como elementos socialmente construídos na história da humanidade, os esportes carecem de subsídios específicos para seu desenvolvimento em qualquer âmbito, a partir de conhecimentos específicos que contemplem suas características específicas, transpondo-as ao processo de ensino-aprendizagem. Nessa perspectiva, Garganta (1998) aponta três possibilidades de enfoque didático-metodológico para abordagem dos esportes, os quais podem centrar-se na Técnica, em Jogos Formais ou em Jogos Condicionados.

Conforme apontam as produções acadêmicas nacionais e internacionais referentes a métodos de ensino da Educação Física, atualmente, o ensino por meio de jogos vem se difundindo com aceitação considerável (GRAÇA; MESQUITA, 2007). As propostas de ensino a partir de jogos foram alicerçando-se nas décadas de 1960 e 1970, a partir da crítica ao ensino tecnicista (CÓSSIOBOLAÑOS et al, 2009; BOLONHINI; PAES, 2009; GRAÇA; MESQUITA, 2007). Bunker e Thorpe (1982), Hopper (2002) e Holt, Strean e Bengoechea (2002) consentem quanto à insipiência do tecnicismo como método de ensino esportivo, ao ressaltarem o insucesso na realização das "inflexíveis" ações do jogo, a falta de criticidade quanto ao esporte e seus princípios inerentes, a baixa autonomia dos alunos e o reducionismo quanto à compreensão da especificidade da Educação Física como área de conhecimento.

Com intuito de apresentar uma sistematização didático-metodológica mais coerente com as características da dinâmica dos esportes, Bunker e Thorpe sistematizaram oficialmente o modelo Teaching Games for Understanding (TGfU) no ano de 1982. A principal contribuição do modelo TGfU foi alterar o enfoque aos elementos táticos e às problemáticas que deles surgem para posterior desenvolvimento das ações de jogo propriamente ditas. A proposta do TGfU é simples e diretiva: desenvolver as ações de jogo a partir de sua relevância tática. Isso se traduz em construir situaçõesproblema, estrategicamente direcionadas, para condicionar a descoberta dos alunos ${ }^{1}$, a qual resultará nas ações que o professor visa desenvolver no processo.

Contudo, essa tarefa didático-pedagógica é complexa, demanda conhecimento específico do professor em relação ao esporte que se está desenvolvendo. Preocupados em apresentar subsídios que fortalecessem essa proposta metodológica, Thorpe, Bunker e Almond (1984) propuseram quatro Princípios Pedagógicos para o desenvolvimento dos esportes para a compreensão, que são a

\footnotetext{
${ }^{1}$ Nesse ensaio, quando se menciona o termo aluno, entendem-se contemplados também atletas, participantes ocasionais e demais possíveis sujeitos do processo de ensino-aprendizagem, em suas múltiplas facetas de manifestação.
} 
Seleção do Tipo de Jogo, a Modificação por Representação, a Modificação por Exagero e a Adaptação da Complexidade Tática. Esses Princípios Pedagógicos têm objetivo de balizar a prática do professor de Educação Física², desde o processo de planejamento e seleção de conteúdos até a intervenção pedagógica.

Entretanto, como o TGfU tem a prerrogativa de ensinar para a compreensão da dinâmica dos esportes, apenas dominar os Princípios Pedagógicos não é suficiente para o professor entender e desenvolver um esporte com profundidade. A partir disso, torna-se fundamental adotar um conhecimento científico que possibilite a compreensão da organização interna dessas manifestações. Nesse sentido, a Praxiologia Motriz destaca-se como uma teoria científica especificamente sistematizada para a análise da lógica interna dos jogos e dos esportes. Com conhecimentos solidamente estabelecidos, a Praxiologia Motriz apresenta ferramentas de análise que evidenciam dos elementos mais amplos aos mais específicos de uma prática motriz, desvelando as características da sua lógica interna.

Com esse panorama, a problemática em voga para esse ensaio é: como se dá a articulação dos conhecimentos da Praxiologia Motriz com os Princípios Pedagógicos do modelo Teaching Games for Understanding? Nesse sentido, o objetivo geral desse artigo é articular os Princípios Pedagógicos do modelo Teaching Games for Understanding com conceitos da Praxiologia Motriz. Em seguida, serão apresentados os caminhos metodológicos adotados nessa pesquisa, seguido da caracterização da Praxiologia Motriz e dos Princípios Pedagógicos do TGfU, finalizando com a articulação entre os dois temas, com foco no desenvolvimento da compreensão da lógica interna dos esportes.

\section{METODOLOGIA}

Esse ensaio visa estabelecer discussões entre conceitos e propostas, assim como suas contribuições no esclarecimento dos fenômenos sociais, articulando suas potencialidades como ferramentas didáticas. Nesse sentido, essa investigação constitui-se de uma pesquisa teórica, que se dedica a desenvolver e discutir conceitos, estruturar quadros de referência e estudar teorias (DEMO, 1995). Esse estudo também se configura de natureza exploratória, ao se dedicar a "desenvolver, esclarecer e modificar conceitos e ideias, tendo em vista a formulação de problemas mais precisos ou hipóteses pesquisáveis para estudos posteriores" (GIL, 2008, p. 27). Richardson (2012) pontua

\footnotetext{
${ }^{2}$ Assim como o uso global do termo aluno, entende-se como professor de Educação Física todos os profissionais capacitados a desenvolver o esporte, desde treinadores a professores de Educação Básica.
} 
que as pesquisas exploratórias buscam descobrir relações entre os fenômenos, no sentido de conhecer e, sobretudo, delimitar essas aproximações conceituais.

Para seleção das obras contempladas no processo de pesquisa bibliográfica, consideraram-se os critérios apontados por Salvador (1986) para delimitação do referencial teórico, que são os parâmetros temático, linguístico, cronológico e as principais fontes. Consideraram-se, então, obras que tematizaram o método Teaching Games for Understanding, em virtude de os Princípios Pedagógicos pertencerem ao debate desse modelo de ensino esportivo.

Quanto à delimitação do idioma das obras que tematizaram os Princípios Pedagógicos do TGfU, considerou-se os estudos redigidos em português e, principalmente, em inglês pela estruturação da base teórica do método ter se dado em países de língua inglesa (Inglaterra, Estados Unidos, Austrália), além de pesquisas em espanhol. No que se refere às obras sobre Praxiologia Motriz, foram utilizadas, prioritariamente, produções escritas em espanhol, pela consolidada disseminação e discussão dos conhecimentos praxiológicos na Espanha, bem como de investigações em português.

Não se estabeleceu um recorte cronológico quanto a seleção das obras, em virtude das matrizes teóricas de ambos elementos dessa pesquisa já virem se desenvolvendo e aprimorando seus conceitos há alguns anos, o que poderia não contemplar obras substanciais para a discussão proposta. Como principais fontes teóricas, utilizou-se dos estudos de Bunker e Thorpe, idealizadores do método TGfU, e os de Pierre Parlebas, responsável pela criação da Praxiologia Motriz. Também se contemplou outros autores como Lagardera e Lavega (2003), Hernández Moreno e Rodríguez Ribas (2004), Holt, Strean e Bengoechea (2002), Kirk e MacPhail (2002), Hooper (2002), Almond (2015), que foram primordiais para a o avanço e consolidação desses dois conhecimentos no cenário acadêmico.

Para o processo de busca das bibliografias contempladas nesse ensaio, fez-se uso de indexadores de periódicos nacionais e internacionais (Scielo, LatIndex, Periódicos da CAPES, Scopus) e do Google Acadêmico, além do Sistema de Bibliotecas de uma universidade pública e do acervo pessoal dos pesquisadores, dos quais se utilizou dos termos "Teaching Games for Understanding", "Princípios Pedagógicos" e "Ensino Para Compreensão" no mecanismo de busca. Os artigos contemplados por essas palavras-chave passaram por uma filtragem, a partir da leitura de seus resumos e da consonância de seus objetivos com suas possibilidades de contribuição para a investigação. Como critério de inclusão, consideraram-se, nesse estudo, as publicações que, além de conter alguma das palavras-chave em seu título ou resumo, também apresentassem uma discussão teórica ou revisão de literatura sobre o modelo TGfU, contabilizando 17 artigos no total. Adotou-se esse critério com objetivo de selecionar estudos que se debruçaram em debater os Princípios 
Pedagógicos do modelo TGfU e seus aspectos teóricos, evitando pesquisas que apenas utilizaramno como um modelo de aplicação, para que se conseguisse densidade teórica suficiente para subsidiar o debate da presente pesquisa. Salienta-se também que alguns artigos em outros idiomas, principalmente em inglês, não se encontravam disponíveis gratuitamente nas páginas online dos periódicos, o que restringiu o acesso a algumas obras.

Para análise das pesquisas que tematizaram o TGfU, utilizou-se do fichamento para categorização dos conhecimentos evidenciados nas obras contempladas no escopo dessa investigação, sistematizando as investigações encontradas em dois eixos temáticos: estudos conceituais ou investigações propositivas. Esse processo possibilitou que se agregassem as informações contidas na produção científica considerada nesse ensaio.

Ao considerar a densidade teórica da Praxiologia Motriz, evidenciada na literatura, faz-se necessário caracterizar alguns elementos referentes a essa área de conhecimento, visto que serão debatidos com ênfase nas articulações com os Princípios Pedagógicos do TGfU. Optou-se, estrategicamente, pela apresentação, a priori, da Praxiologia Motriz, para delimitação dos conceitos que serão explorados e por se constituir da base teórica que embasa a presente investigação. Em sequência serão apresentados os Princípios Pedagógicos e suas características e, por fim, a articulação deles com os conceitos praxiológicos, no sentido de auxiliar o desenvolvimento do esporte para compreensão.

\section{PRAXIOLOGIA MOTRIZ: teoria científica para análise de jogos e esportes}

No que concerne entender as particularidades de um esporte ou jogo, a Praxiologia Motriz estabelece-se como uma área de conhecimento dedicada a analisar a dinâmica de funcionamento das manifestações da cultura corporal de movimento. Para Parlebas (2001, p. 354), a Praxiologia Motriz constitui-se como "a ciência da ação motriz e especialmente das condições, modos de funcionamento e os resultados do seu desenvolvimento". Essa definição, mesmo que bastante abrangente, dá conta de apresentar a essência da proposta praxiológica, já que o conceito de ação motriz é seu eixo norteador.

Esse conceito apresenta significativa relevância na visão praxiológica, ao ponto de adotar-se o uso frequente da expressão Teoria da Ação Motriz como denominação dessa teoria científica. Parlebas (2001) entende que todas as práticas motrizes se constituem de sistemas praxiológicos, o que remete a uma complexa trama de relações que só podem ser entendidas em seus contextos. De uma forma geral, pode-se afirmar que a Praxiologia Motriz objetiva estudar a lógica interna dos jogos e dos esportes (LAGARDERA; LAVEGA, 2003). 
Parlebas (2001) considera a ação motriz como a resultante da inserção do sujeito no sistema praxiológico, a qual se constitui como "processo de realização das condutas motrizes de um ou vários sujeitos que atuam em uma situação motriz determinada" (PARLEBAS, 2001, P. 41). A ação motriz caracteriza-se da materialização da atuação corporal dos jogadores, as quais são abarcadas de sentido a partir do sistema em que estão inseridas, ao considerar as inúmeras possibilidades de ação concedidas pelas especificidades da lógica interna de cada jogo, pautadas em suas regras.

Outro conceito que subsidia a perspectiva de entendimento praxiológico é o que se refere à lógica interna. Parlebas (2001) a define como um conjunto de características que remetem consequências na realização das ações motrizes. A lógica interna apontará a forma como os jogadores poderão atuar no contexto do jogo, a partir de suas regras, delimitando as possibilidades de interação do jogador com espaço, demais jogadores, material e tempo.

Para Praxiologia Motriz, essa dinâmica relacional dos jogos e esportes é um elemento chave para compreensão de um esporte, em especial na égide do conceito de interação motriz. Parlebas (2001) considera que uma interação motriz se estabelece quando, no momento em que determinado participante realiza uma tarefa motriz, seu comportamento motor influencia visivelmente nas ações motrizes de um ou de vários dos participantes. Nesse sentido, há uma interferência dos outros jogadores na conduta de quem realiza uma ação motriz, que se estabelece por meio de trocas de mensagens e processos de leitura de jogo, os quais são veiculados por meio da semiotricidade.

Parlebas (2001, p. 406) caracteriza a semiotricidade como "natureza e campo das situações motrizes, consideradas desde o ponto de vista da aplicação de sistemas de signos associados diretamente à conduta motriz dos participantes”. Essa perspectiva atrela significado às ações motrizes, ao apontar que quaisquer atuações dos jogadores serão emissoras de mensagens, as quais são passíveis de interpretação pelos outros participantes, constituindo o espectro da Comunicação Práxica (PARLEBAS, 2001).

A Comunicação Práxica engloba as características definidoras da lógica interna, o que permite compreender as ações dos jogadores à medida que se inserem em uma unidade global, atrelando sentido as suas atuações (PARLEBAS, 2001). Este conceito subdivide-se em Comunicação Práxica Direta e Comunica Práxica Indireta. A Comunicação Práxica Direta faz menção à forma como as ações serão executadas em relação aos companheiros e aos adversários (PARLEBAS, 2001). Esse tipo de comunicação práxica é responsável por guiar todas as ações que acontecerão no jogo, ao passo que caracterizam as interações motrizes de comunicação (cooperação) e de contracomunicação (oposição). A comunicação será configurada toda vez em que se objetivar a facilitação das ações e os processos de leitura do(s) outro(s) jogador(es), o que configura a cooperação. Já a contracomunicação, como sua nomenclatura sugere, está vinculada ao 
processo de dificultar ações e interpretações do(s) outro(s) jogador(es), ilustrando a oposição (RIBAS, 2014).

Já a Comunicação Práxica Indireta se associa à decodificação dos comportamentos motores dos demais jogadores como veículos de mensagem, a qual também se subdivide em duas possibilidades de manifestação: o gestema e o praxema. O gestema está vinculado a gestos e códigos realizados pelos praticantes, como substituição ao uso da fala, para realizar uma indicação específica, um signo pré-estabelecido que indica determinada informação para os jogadores que o conhecem (PARLEBAS, 2001).

O praxema, por sua vez, constitui-se da "conduta motriz de um jogador como um símbolo, cujo significante é o comportamento motor observável e cujo significado é o projeto tático correspondente a dito comportamento, tal e como é percebido" (PARLEBAS, 2001, p. 349). Nesse sentido, o praxema é a interpretação subjetiva da atuação concreta dos outros jogadores como algo que significa, que transmite informação, o que acarreta em antecipações e decisões motrizes que interferem diretamente no comportamento motor de quem realiza a leitura. Dessa forma, a Comunicação Práxica Indireta atrela significado às ações e comportamentos dos participantes, ao interferir diretamente nas ações motrizes dos jogadores, com base nos processos de leitura gestêmica e praxêmica.

Essas são apenas algumas das ferramentas da Praxiologia Motriz para análise dos jogos e esportes $^{3}$. Esses conceitos abordados são peças-chave para que se de desenvolva a compreensão sobre a dinâmica de funcionamento de alguma prática motriz. Nesse sentido, os conhecimentos evidenciados pela Praxiologia Motriz podem contribuir diretamente no processo de ensinoaprendizagem para a compreensão do esporte, ao identificar as principais características atinentes à lógica interna, ou seja, da própria dinâmica do jogo. Com essa ideia, o próximo passo desse ensaio é apresentar os Princípios Pedagógicos do TGfU para posterior articulação com os conceitos praxiológicos abordados nessa seção.

\section{PRINCÍPIOS PEDAGÓGICOS DO MODELO TEACHING GAMES FOR UNDERSTANDING}

Para consolidar sua proposta de ensino para compreensão, Thorpe, Bunker e Almond (1984), após sua primeira publicação sobre o método TGfU, propuseram quatro Princípios

\footnotetext{
${ }^{3}$ Há outros conceitos que servem de base para a análise das práticas motrizes segundo a Praxiologia Motriz, como os Universais (para análise aprofundada da lógica interna de um esporte) ou a etnomotricidade (interlocuções socioculturais das práticas). No entanto, optou-se pelos conceitos anteriormente expostos por se tratar de um primeiro movimento aproximativo entre os Principios Pedagógicos e os conhecimentos praxiológicos, bem como por não se ter delimitado a discussão a um esporte apenas.
} 
Pedagógicos para embasar o desenvolvimento da compreensão do jogo a partir desse modelo metodológico. Clemente (2012) e Graça e Mesquita (2007) apontam que Thorpe, Bunker e Almond desenvolveram a Seleção do Tipo de Jogo, a Modificação por Representação, a Modificação por Exagero e a Adaptação da Complexidade Tática como elementos norteadores do planejamento e execução das aulas no modelo TGfU.

Esses Princípios Pedagógicos consolidam-se como referências didáticas substanciais para as modificações realizadas nas estruturas e nas regras dos jogos condicionados, já que é por meio dessas alterações que se enfatizará o entendimento da lógica de funcionamento e se condicionará a atuação dos alunos a partir dos objetivos estabelecidos (THORPE, BUNKER \& ALMOND, 1984; CLEMENTE, 2014; ALMOND, 2015). O modelo TGfU possibilita o desenvolvimento desses Princípios Pedagógicos em sua organização didático-metodológica, entretanto, sua utilização no ensino esportivo não está restrita a esse modelo. Qualquer abordagem metodológica de ensino do esporte pode fazer uso desses elementos, desde que considere suas características específicas.

O primeiro Princípio Pedagógico, a Seleção do Tipo de Jogo, constitui-se da atenção do professor no planejamento e na escolha das estruturas didáticas utilizadas no processo de ensinoaprendizagem. Os jogos condicionados propostos devem possibilitar uma multiplicidade de experiências que condicionem à compreensão de similaridades e diferenças entre as modalidades (CLEMENTE, 2012). Nesse sentido, Thorpe, Bunker e Almond (1984) evidenciaram a necessidade da adoção de um sistema que classifique essas manifestações esportivas a partir de suas características. Assim, basearam-se na proposta de Ellis (1983), que categoriza os esportes pela seguinte categorização: jogos de invasão; jogos de campo e taco; jogos de muro/parede; jogos de quadra dividida e jogos de alvo (THORPE, BUNKER \& ALMOND, 1984; FOTIA, 2013).

Thorpe, Bunker e Almond (1984) propõem que, com base nessa classificação, torna-se possível instigar a percepção de elementos básicos do funcionamento dos jogos que se entrelaçam entre as modalidades, situando-as na mesma categoria. Segundo os autores, isso permite desenvolver e transferir esses denominadores comuns para o aprendizado das diferentes práticas, como pressupostos que culminem na compreensão do funcionamento dos jogos de mesma classificação (THORPE, BUNKER \& ALMOND, 1984).

Já o Princípio Pedagógico de Modificação por Representação indica que todas as estruturas propostas precisam refletir as características do jogo formal, com o intuito de manter os elementos que sustentam a dinâmica de funcionamento de determinado esporte (THORPE, BUNKER \& ALMOND, 1984, BUNKER \& THORPE, 1986; ALMOND, 2015; CLEMENTE, 2012). Assim, as estruturas didáticas devem condicionar a compreensão tática da forma de jogo que se objetiva no processo, na direção de potencializar o entendimento e as tomadas de decisão, com base em 
situações-problema semelhantes às que se estabelecem no jogo. Tan, Chow e Davids (2011) salientam que a Modificação por Representação é a responsável por manter a relação entre informação e ação no que tange a estrutura do jogo formal, de maneira próxima à sua manifestação original. Dessa forma, a Modificação por Representação irá gerir por que e como o professor proporá as situações do jogo condicionado, assim como suas orientações quanto às tarefas latentes ao jogo.

O Princípio Pedagógico de Modificação por Exagero configura-se como "manipulação das regras de jogo, do espaço e do tempo de modo a canalizar a atenção dos jogadores para o confronto com determinados problemas tácticos" (GRAÇA \& MESQUITA, 2007, P. 402). Esse Princípio Pedagógico assinala que as estruturas didáticas devem ser construídas a partir de alterações nas regras do jogo, com o objetivo de salientar determinado comportamento técnico-tático dos jogadores (THORPE, BUNKER \& ALMOND, 1984; CLEMENTE, 2012). A Modificação por Exagero precisa refletir o objetivo estabelecido ao instigar uma atuação específica por parte dos alunos, por intermédio de estímulos estabelecidos por pontuação, vantagens/desvantagens, materiais alternativos ou qualquer outra alteração à regra ou no contexto do jogo.

Por exemplo, para ensinar a armação ofensiva do Voleibol na iniciação esportiva, pode-se realizar um jogo com participantes e espaço reduzidos (quatro contra quatro) propondo que quando o ponto for finalizado com ataque oriundo da relação entre recepção, levantamento e ataque, serão valorados três pontos à equipe que realizá-lo. Essa alteração exagerada na pontuação estimulará que os alunos organizem essa armação ofensiva para ter proveito da nova regra proposta. Além disso, essa estrutura didática manteria as caraterísticas do Voleibol formal, como orienta o Princípio de Modificação por Representação.

Entretanto, de pouco adianta propor estruturas didáticas baseadas em jogos condicionados se os alunos não apresentarem condições técnico-táticas mínimas para realização das tarefas propostas. É pautado nisso que se estabelece o quarto Princípio Pedagógico do TGfU, Adaptação da Complexidade Tática. Ele corresponde ao estabelecimento de situações-problema que sejam correspondentes às competências e potencialidades dos alunos (TAN, CHOW \& DAVIDS, 2011).

Thorpe, Bunker e Almond (1984), ao proporem a Adaptação da Complexidade Tática, advertem que é necessário iniciar com estruturas didáticas de nível de assimilação tática simples e que os aspectos mais complexos sejam inseridos a medida em que os alunos apresentarem capacidade para solucioná-los satisfatoriamente (CLEMENTE, 2012; ALMOND, 2015). Face ao exposto, é nítida a relevância da adequação das tarefas de aprendizagem de forma apropriada às possibilidades dos alunos, ao passo que os desafie e, simultaneamente, possibilite-os alcançar o sucesso interventivo (TAN, CHOW \& DAVIDS, 2011). Contudo, é eminentemente necessário 
manter a dinâmica de funcionamento do jogo, todas as alterações devem considerar as capacidades dos alunos, mas com a advertência de manter as características básicas constituintes da dinâmica do jogo em questão.

Tomando como exemplo a aplicação do Princípio de Adaptação da Complexidade Tática no ensino do Handebol, pode-se estabelecer uma estrutura didática em espaço reduzido em que só seja possível realizar passes quicados e que os gols só sejam validados quando o arremesso for executado em suspensão. Essa proposta demanda dos alunos controle e domínio com a bola de Handebol, principalmente no que se refere à execução do passe quicado, bem como de um arremesso em suspensão consistente para conceder a possibilidade de marcar gols apenas por esse tipo de arremesso. Nesse sentido, adotar essa estrutura com um grupo de alunos que não tenha alguma dessas capacidades bem desenvolvidas pode dificultar ou até mesmo inviabilizar a atividade proposta. A Adaptação da Complexidade Tática apresenta-se com intuito de assegurar que os jogos condicionados aplicados nas aulas estejam adequados às habilidades que os alunos evidenciam, alterando as estruturas do esporte formal para condicionar sua compreensão.

Tendo em vista a disseminação das discussões instigadas pelo modelo TGfU a nível mundial, muitos teóricos trouxeram contribuições a essa proposta metodológica (SÁNCHEZGÓMEZ, DEVÍS-DEVÍS \& NAVARRO-ADELANTADO, 2014). Uma dessas contribuições foi realizada por Holt, Strean e Bengoechea (2002) que se pautaram nas considerações expostas por Allen Wade, em 1970, quanto aos elementos básicos constituintes do jogo de futebol, para proporem mais um Princípio Pedagógico: o Princípio de Jogo. Os autores entendem que é necessário proporcionar ao(s) aluno(s) a consciência da estratégia adotada pela equipe em relação à situação-problema do jogo.

Além disso, perceber os aspectos táticos inerentes à modalidade é elemento central para condicionar a compreensão do jogo, bem como das ações que dele resultam, ao considerar sua relevância para a organização da equipe no contexto do jogo. O avanço pedagógico do Princípio de Jogo proposto por Holt, Strean e Bengoechea (2002) constituiu-se em instigar o aluno a entender o seu papel na estratégia da equipe, o que realmente possibilitará que ele atue categoricamente a partir das necessidades do contexto tático.

Posto fim a apresentação das características dos Princípios Pedagógicos do modelo TGfU, o próximo passo dessa investigação é articular os Princípios Pedagógicos com os conhecimentos da Praxiologia Motriz. Algumas proposições serão apontadas no sentido de potencializar a compreensão do jogo objetivado pelos parâmetros estabelecidos a partir dos Princípios Pedagógicos para o processo de ensino-aprendizagem para compreensão da lógica interna dos esportes. 


\section{ORIENTAÇÕES PRAXIOLÓGICAS AOS PRINCÍPIOS PEDAGÓGICOS DO TGFU A LUZ DO CONCEITO DE LÓGICA INTERNA}

A priori, é necessário esclarecer que as proposições que serão realizadas entre a articulação dos Princípios Pedagógicos com a Praxiologia Motriz têm objetivo de contribuir para o processo de ensino-aprendizagem dos esportes para a compreensão. Em nenhum momento este ensaio busca desmerecer a excelente proposição de Thorpe, Bunker e Almond (1984), mas sim apresentar elementos que podem contribuir para o desenvolvimento da compreensão da lógica interna dos esportes. Algumas considerações aqui realizadas apontam outras alternativas, a partir de uma concepção praxiológica, para o trato com o esporte.

Em se tratando do primeiro Princípio Pedagógico, Seleção do Tipo de Jogo, o qual visa possibilitar transferências de aprendizagem entre as práticas motrizes de mesma categoria, percebese que a classificação de Thorpe, Bunker e Almond (1984)4 , baseada na proposição de Ellis (1983), não contempla os conhecimentos base sobre a organização da lógica interna das práticas motrizes (FOTIA, 2013). Constata-se que a categorização exposta nessa sistematização engloba os elementos constituintes da lógica interna de forma aleatória a medida em que convém a estruturação proposta. Para Fotia (2013), essa classificação é restrita às descrições das características mais aparentes das práticas, o que dificulta o estabelecimento de critérios consistentes para a classificação dos esportes e fragiliza o processo de ensino-aprendizagem voltado à compreensão do jogo.

A utilização dessa categorização de famílias de esportes se fez pela similaridade das problemáticas, objetivos, características e intenções apresentadas pelas práticas situadas em mesma categoria. A partir disso, Thorpe Bunker e Almond (1984) compreendem que as estruturas didáticas construídas podem remeter-se diretamente às categorias propostas nessa sistematização, ao passo em que apresentam um denominador comum no que tange a dinâmica de funcionamento das práticas contempladas em cada grupo. Contudo, essa proposição mostra-se frágil no que no que tange à classificação das práticas motrizes a partir de suas lógicas internas. Essa sistematização desconsidera a principal característica que substancia a lógica interna de qualquer prática: as interações motrizes estabelecidas entre os jogadores.

Ilustrando a limitação dessa proposta, Fotia (2013), ao discorrer sobre o Voleibol e sua lógica interna, questionando a classificação dessa prática motriz como esporte de quadra dividida, juntamente com Tênis e Badminton. $\mathrm{O}$ autor tece duras críticas a essa proposta ao apontar que não

\footnotetext{
${ }^{4}$ Relembrando o que já foi mencionado anteriormente, essa divisão constitui-se em cinco grandes grupos de modalidades, que são: jogos de invasão, jogos de campo e taco, jogos de muro ou parede, jogos de alvo e jogos de quadra dividida (Thorpe, Bunker \& Almond, 1984)
} 
se mostra prudente considerar esses esportes similares unicamente pelo fato de os campos serem invioláveis (separados por uma rede) ou pela impossibilidade de retenção da bola.

Algumas particularidades substanciais sobre as lógicas internas do Voleibol e do Tênis são exemplificadas por Fotia (2013) para corroborar a fragilidade dessa sistematização. A possibilidade de quicar a bola, concedida apenas no Tênis, as interações com os materiais específicos de cada um deles, as características das ações motrizes de cada sistema a partir de suas regras e, principalmente, as interações motrizes de cooperação e oposição totalmente distintas entre essas práticas motrizes, constituem-se como características insustentáveis para considerá-los pertencentes a um grupo de práticas semelhantes ou de possibilidades de transferência direta.

Fotia (2013) finaliza a sua exposição salientando que o Voleibol é considerado um esporte de cooperação-oposição, o que torna ainda mais incabível sua aproximação com Tênis, esporte de oposição - o jogo de duplas no Tênis apresenta-se também como uma prática de cooperaçãooposição, contudo é a oposição quem baliza, prioritariamente, as ações dos jogadores. Questiona-se: será que o Tênis, uma modalidade em que se age sozinho na devolução da bola, que usa implementos (raquete), que permite um quique da bola ao chão, possibilidade de sacar duas vezes e relevância muito maior da oposição pode apresentar transferências de aprendizagem relevantes ao ponto de sustentar todo um processo de ensino-aprendizagem do Voleibol apenas por ter uma rede que divide o campo? As evidências de lógica interna não apontam para essa possibilidade.

Essa incongruência quantos aos critérios utilizados não se confirma apenas na categoria de classificação de esportes de quadra dividida, mas também entre os outros grupos propostos. Nos jogos de alvo (golfe, bilhar e boliche) e nos jogos de campo e taco (beisebol e críquete), por exemplo, considera-se apenas os objetivos motores das práticas, ignorando as diferentes interações motrizes que são exercidas com materiais e espaço dos jogos, elementos essenciais da lógica interna e, consequentemente, interferentes nas ações motrizes. Enquanto isso, nos esportes de quadra dividida, o critério utilizado faz menção ao espaço de jogo e ao objetivo motor, desconsiderando novamente as interações motrizes de cooperação e oposição, ao tomar apenas a rede divisória como aspecto comum a essas práticas, o que torna a classificação pouco fidedigna no que se refere à criteriosidade adotada.

Qualquer classificação que busque ser rigorosa deve relevar as características do objeto de análise, bem como despir-se de superficialidades e aparências, em um sentido único na direção do desvelar das identidades dos sistemas praxiológicos, as quais são singulares e complexas (LAGARDERA; LAVEGA, 2003). Além disso, uma sistematização, para ser global, necessita respeitar dois critérios básicos: exaustividade e exclusividade. A exaustividade constitui-se da possibilidade de classificar inúmeras vezes qualquer prática motriz a partir de critérios rígidos, 
independentemente de suas características, ao passo que a exclusividade dita que a prática motriz pode pertencer apenas a uma categoria de análise, corroborando sempre o mesmo resultado (FAGUNDES, RIBAS, FRANCHI, LANES, \& OLIVEIRA, 2016).

É nesse sentido que a Praxiologia Motriz, como teoria científica que estuda lógica interna, propõe que para compreender a estrutura de um esporte, é necessário que se atente aos quatro elementos essenciais da lógica interna: espaço, tempo, material e demais jogadores. Se considerarmos a classificação elegida pelo TGfU, constata-se que a componente de interação entre os jogadores não é considerada para classificar esses esportes, o que torna frágil uma proposição que tem como intuito ensinar a lógica do jogo. É substancial que o aluno entenda a forma como ele precisa interagir com companheiros e adversário em cada esporte, em especial no processo de identificação dos momentos em que essas relações de cooperação e oposição acontecem no jogo.

Exatamente por essa singularidade da lógica interna de cada esporte torna-se insustentável planejar e executar processos de ensino-aprendizagem tendo como foco as possíveis transferências de aprendizagem que podem ser feitas entre esportes de mesma categoria. Não se está afirmando aqui que as transferências de aprendizagem não existem ou são maléficas ao ensino esportivo, pelo contrário, elas existem e, se bem desenvolvidas, são fundamentais. No entanto, como nos demonstra o próprio conceito de lógica interna, cada manifestação é única, extremamente singular, mesmo que se pareça com outro esporte estruturalmente. Não seria mais relevante ao professor munir-se de ferramentas para melhor compreender a forma como está estruturada essa lógica interna, aprofundando nos conhecimentos específicos e potencializando a compreensão da dinâmica do jogo, do que esforçar-se em criar estruturas didáticas que contemplem elementos em comum em práticas motrizes diferentes? O grande avanço do TGfU, como modelo de ensino esportivo, é salientar a compreensão do jogo em seu processo, ao passo que essa perspectiva de ênfase na transferência de elementos de uma prática para outra fragiliza a contextualização da compreensão da dinâmica especificamente intrínseca a cada jogo.

Com esse pressuposto, o Princípio Seleção do Tipo de Jogo pode ser readequado a um aprofundamento do professor quanto ao desvelar das características próprias da prática motriz, no intuito de conhecer sua lógica interna a ponto de desenvolvê-la com mais sapiência. Nesse sentido, propõe-se um novo Princípio Pedagógico, que se denominou Caracterização da Lógica Interna, o qual orienta que, ao invés de preocupar-se em selecionar um "tipo de jogo", se objetive identificar quais elementos da prática motriz em questão devem ser considerados para possibilitar a compreensão de sua lógica interna. Nessa perspectiva, não se busca criar elos para transferência de aprendizagem entre práticas motrizes de mesmo tipo, ao partir do pressuposto de que as práticas 
motrizes apresentam lógicas internas especificamente complexas e que devem ser compreendidas em seu próprio sistema.

Isso não significa que não se possam traçar paralelos entre as práticas motrizes para ilustrar suas características convergentes e/ou divergentes. No entanto, compreende-se que estruturar o processo de ensino-aprendizagem na concepção de transferência de aprendizagem é insipiente aos objetivos que o próprio TGfU propõe. Com o Princípio de Caracterização da Lógica Interna, ao tematizar a lógica interna de uma prática específica ao invés de uma classe de esportes, consolida a compreensão da lógica interna do referido jogo e, a partir disso, fortalece-se as comparações, inclusive as transferências, com as demais práticas, baseando-se nessa dinâmica de funcionamento de cada jogo, já assimiladas.

No que se refere ao Princípio de Modificação por Representação o qual defende que é preciso manter a lógica interna do jogo formal em relação aos jogos condicionados/estruturas didáticas, novamente o conceito de lógica interna ganha destaque. Ou seja, as características substanciais em relação às interações motrizes com os outros jogadores, com o material, com o espaço e com o tempo do jogo devem apresentar-se de maneira semelhante ao jogo formal. É prudente apontar os elementos da lógica interna que serão modificados em cada estrutura didática, a partir de sua primordialidade para o funcionamento daquele sistema praxiológico, e como essas alterações influenciarão nas condutas motrizes ${ }^{5}$ dos alunos (PARLEBAS, 2001). Esse momento consiste em focar na prática motriz em questão para entender quais aspectos são substanciais para remeter à lógica interna do jogo.

Como exemplo, ao propor um jogo condicionado para o ensino do Voleibol baseado no método TGfU, é mais prudente manter elementos específicos de sua lógica interna, como a cooperação e oposição simultâneas, a interação com o material (bola) se dar sempre por intermédio do ato de rebater e as atuações dos jogadores acontecerem sempre de maneira alternada. Essas características são substanciais para que a lógica interna do Voleibol se estabeleça no jogo, ao passo que sua manutenção nas estruturas didáticas é fundamental. Por isso, defende-se a apropriação do professor quanto aos conhecimentos da Praxiologia Motriz para embasar sua atuação e condicionar a compreensão da lógica interna dos jogos por parte dos alunos.

Nesse viés, a materialização da ação motriz dos jogadores a partir da lógica interna se dá pelas interações motrizes por eles estabelecidas no decorrer do jogo (PARLEBAS, 2001; LAGARDERA \& LAVEGA, 2003). Essas interações suscitam constantes trocas de mensagens

\footnotetext{
${ }^{5}$ Conduta motriz é a apropriação da ação motriz por parte do praticante. A partir desse processo, a conduta motriz dota de significado e de características pessoais as ações motrizes dos jogos e esportes, tornando-as unicamente pertencentes a quem as produz (PARLEBAS, 2001; LAGARDERA \& LAVEGA, 2003).
} 
(facilitadas ou dificultadas) que se concretizam em processos de leitura de jogo - capacidade cognitiva elementar para o sucesso interventivo do esporte (RIBAS, 2014). É por essa razão que a manutenção da lógica interna, assegurada pelo Princípio de Modificação por Representação, é eixo norteador do processo de ensino-aprendizagem para a compreensão. Sem esse subsídio conceitual, há grande chance de as modificações realizadas na prática pedagógica não contemplarem elementos fundamentais para manutenção dinâmica de funcionamento do jogo formal, indeferindo a compreensão da lógica interna de forma adequada.

Apenas aliar as particularidades do jogo condicionado com a manifestação do jogo formal não é o suficiente para guiar um processo de ensino-aprendizagem. Para isso, constituiu-se o Princípio de Modificação por Exagero, que se configura em alterações específicas à lógica interna do jogo formal, no sentido de estimular um comportamento tático ou uma ação motriz específica (BUNKER \& THORPE, 1986). Essas modificações servirão para guiar as ações pretendidas em relação aos alunos, ao conceder a pontuação apenas a partir de algum elemento, restringir a atuação dos jogadores à determinadas ações motrizes do jogo ou até mesmo valorar maior pontuação para jogadas ou construções táticas específicas.

Ao considerar que a Praxiologia Motriz entende as práticas motrizes como sistemas praxiológicos, os quais emergem ações motrizes específicas, fica evidente a necessidade de o professor compreender como as alterações dos elementos da lógica interna interferem nas ações motrizes dos jogadores, em consonância com aquilo que se objetiva desenvolver. Clemente (2014, p. 327) é taxativo ao afirmar que, na Modificação por Exagero, “[...] importa que o professor conheça de forma inequívoca os fundamentos e dinamismo intrínseco do jogo no sentido de exponenciar a prática de determinado conteúdo tático". Para isso, atentar às modificações propostas nas interações com diferentes tipos de material, com o espaço, com os jogadores e com o tempo do jogo irá modificar a lógica interna dos jogos condicionados o que auxilia na criação situaçõesproblema que enfatizem, preferencialmente, a leitura dos gestemas e/ou praxemas mais frequentes no jogo, fortalecendo a tomada de decisão.

Tomando como exemplo uma atividade para o desenvolvimento das situações de ataque e bloqueio no Voleibol, a qual o atacante deve considerar a atuação dos bloqueadores para optar pela direção do seu ataque. Pode-se, em um primeiro momento, indicar o local o qual o bloqueador protegerá e condicionar a leitura do atacante com o estímulo visual do comportamento adversário. Em sequência, a estrutura didática pode avançar o nível de complexidade ao atrelar aleatoriedade na atuação do bloqueador, desenvolvendo a leitura de jogo em concomitância à realização do ataque.

Nessa ilustração, o desenvolvimento das específicas ações motrizes está diretamente contextualizado com suas aplicações no contexto do jogo, o que condiciona o entendimento de sua 
relevância para a lógica interna do Voleibol. Essa proposição, mais uma vez, corrobora que o alicerce estruturado a partir dos conhecimentos praxiológicos elenca elementos pontuais para prática do professor de Educação Física com base nos Princípios Pedagógicos do TGfU.

O Princípio Pedagógico da Adaptação da Complexidade Tática diz respeito à adequação da dificuldade das tarefas propostas nos jogos condicionados a partir do nível de compreensão e de habilidade dos alunos (TAN, CHOW \& DAVIDS, 2011). Considerando os conhecimentos da Praxiologia Motriz, é preciso criar situações em que as interações motrizes de cooperação e/ou oposição, características de cada prática motriz, estabeleçam-se de forma adequada à capacidade dos alunos. Uma estratégia didática usual é a priorização da cooperação no princípio do processo, visto que sua característica de facilitação de ações e emissões de mensagens aos outros jogadores torna mais simples a realização das ações motrizes (RIBAS, 2014). Essa estratégia didática deve ser adotada quando os alunos apresentarem dificuldades em conciliar a tomada de decisão com a interpretação das situações de jogo, contudo, sem desconsiderar a oposição presente no jogo, apenas alterando o foco da atividade proposta.

Salienta-se que há uma linha tênue entre a manutenção das interações motrizes do jogo formal e as adequações do nível de exigência tática dos jogos condicionados. Em alguns momentos, talvez seja necessário considerar apenas a cooperação ou a oposição especificamente. Mesmo que a prática apresente essas duas interações em sua lógica interna, há momentos que é preciso simplificar a dinâmica do jogo, para possibilitar o desenvolvimento adequado das ações motrizes e a compreensão da dinâmica do jogo. Desconsiderar de todo o processo alguma dessas interações motrizes descaracterizará a lógica interna do jogo formal, contudo, pode ser uma estratégia didática pontual para que, nas sessões seguintes de aula ou treinamento, os alunos consigam apropriar-se completamente da lógica interna da prática motriz. Esse conflito é substancial à prática do professor, que deve perceber quais elementos precisam ser priorizados, com base na etapa de desenvolvimento dos alunos, dos objetivos e do conteúdo, considerando a particularidade da sua realidade docente.

Isso também se aplica às relações com os materiais, tempo e com o espaço de jogo. É importante proporcionar alternativas que facilitem as ações motrizes dos alunos em relação a suas próprias capacidades, usando elementos como bolas mais leves, quadras e número de participantes reduzidos, raquetes e tacos menores, alvos maiores, redes e tabelas mais baixas, entre outros aspectos (KIRK \& MACPHAIL, 2002; HOOPER, 2002). Ainda é possível propor novas regras para tornar as ações motrizes menos complexas. No entanto, o professor deverá avaliar: como essas alterações à lógica interna irão interferir nas ações dos alunos; se condizem com os objetivos da aula ou treinamento; e se contempla o Princípio de Modificação por Representação. 
Por fim, o Princípio de Jogo resguarda a atenção do professor à problematização das estratégias, individuais ou coletivas, que são adotadas no contexto do jogo a partir de sua lógica interna específica (HOLT, STREAN \& BENGOECHEA, 2002). Essa preocupação é mais evidente em práticas motrizes de interação (oposição, cooperação ou cooperação-oposição), em virtude da relevância que os aspectos estratégicos apresentam a partir das possibilidades de cooperação ou oposição. Assim, salientar a necessidade de manter o posicionamento, realizar um bom passe, apresentar-se em condições ideais para receber ou forçar a ação menos eficiente do adversário são fatores substanciais para boa atuação no jogo, seja ela individual ou coletiva.

Além disso, o enfoque realizado pelo Princípio de Jogo traz à tona a eminência dos processos de leitura de jogo, seja de companheiros ou adversários, para o sucesso da organização da equipe e o mesmo da atuação individual. Identificar os pontos fortes e fracos da sua equipe e da equipe adversária para optar pela melhor configuração tática a partir desse contexto é tarefa básica para os jogadores compreenderem como balizar sua própria atuação. Em práticas motrizes de oposição, interpretar as qualidades e limitações do adversário é tarefa primordial para conseguir o êxito no jogo, ao adaptar suas ações e estratégias motrizes às características do oponente nas diferentes situações do jogo.

No sentido de sintetizar a articulação realizada entre os Princípios Pedagógicos do TGfU e os conhecimentos da Praxiologia Motriz, estruturou-se uma tabela, contendo uma síntese das discussões realizadas nesse ensaio, expressa logo abaixo. Essa sistematização visa aglutinar os conceitos praxiológicos estruturados em cada um dos Princípios Pedagógicos, na iniciativa de facilitar o manuseio desse material e possibilitar sua aplicação de forma objetiva e simplificada para a prática pedagógica do professor de Educação Física.

TABELA 1 - Articulação entre os Princípios Pedagógicos do TGfU e os conceitos da Praxiologia Motriz

\begin{tabular}{|l|ll|}
\hline \multicolumn{1}{|c|}{ PRINCÍPIOS PEDAGÓGICOS } & \multicolumn{2}{c|}{ CONCEITOS DA PRAXIOLOGIA MOTRIZ } \\
\hline \multirow{2}{*}{ Caracterização da Lógica Interna } & $\checkmark$ & Lógica Interna \\
& $\checkmark$ & Interações Motrizes \\
\hline \multirow{3}{*}{ Modificação por Representação } & $\checkmark$ & Lógica Interna \\
& $\checkmark$ & Interações Motrizes \\
& $\checkmark$ & Leitura de Jogo \\
& $\checkmark$ & Ação Motriz \\
\hline \multirow{3}{*}{ Modificação por Exagero } & $\checkmark$ & Adaptações à Lógica Interna \\
& $\checkmark$ & Leitura Gestêmica \\
& $\checkmark$ & Leitura Praxêmica \\
& $\checkmark$ & Interações Motrizes \\
& $\checkmark$ & Ação Motriz \\
\hline
\end{tabular}




\begin{tabular}{|l|ll|}
\hline \multirow{2}{*}{ Adaptação da Complexidade Tática } & $\checkmark$ & Adaptações à Lógica Interna \\
& $\checkmark$ & Interações Motrizes \\
& $\checkmark$ & Leitura de Jogo \\
& $\checkmark$ & Ação Motriz \\
\hline Princípio de Jogo & $\checkmark$ & Interações Motrizes \\
& $\checkmark$ & Leitura de Jogo \\
\hline
\end{tabular}

Fonte: Elaborado pelos autores.

Essa estrutura é apenas uma indicação, a partir da articulação realizada nesse ensaio, da utilização mais adequada dos conhecimentos da Praxiologia Motriz em cada Princípio Pedagógico. Construiu-se essa sistematização com intuito de apresentar um parâmetro para o processo de ensino-aprendizagem. No entanto, essa proposta é totalmente flexível, não impedindo que outros conhecimentos sejam adicionados na utilização de cada Princípio Pedagógico, bem como possibilitando a transferência de conceitos de um Princípio para o outro a partir das características de cada processo de ensino-aprendizagem.

\section{CONCLUSÕES}

O objetivo dessa investigação foi articular os Princípios Pedagógicos do modelo Teaching Games for Understanding com conceitos da Praxiologia Motriz. A Praxiologia Motriz, como teoria de análise de lógica interna de jogos e esportes, apresenta diversos conceitos e ferramentas para identificar os elementos constituintes da dinâmica de funcionamento das práticas. Os Princípios Pedagógicos balizam um delineamento didático para a atuação do professor de Educação Física, desde seu planejamento até suas intervenções, de modo a materializar a compreensão do jogo em estruturas didáticas totalmente conectadas com a lógica interna do jogo formal.

Evidenciou-se que a potencialidade dessa articulação é o desenvolvimento da compreensão do jogo especificamente vinculado à lógica interna da prática motriz. A Praxiologia Motriz mostrase como uma ferramenta didática que transforma os aspectos subjetivos dos esportes em elementos concretos, os quais são as matérias-primas da prática pedagógica dos professores de Educação Física. Conhecer os elementos constituintes do esporte que se está desenvolvendo, bem como a interferência deles na dinâmica do jogo e nas ações dos alunos, é substancial para que se atinja um processo de ensino-aprendizagem voltado à compreensão. É a partir do manuseio desses elementos e da sabedoria em explorá-los que a prática pedagógica ganha em eficiência e pluralidade de experiências, assim como o papel do professor como mediador desse processo é fundamental. 
Essas são algumas considerações gerais para aplicação dos Princípios Pedagógicos do modelo TGfU pautados em uma interpretação praxiológica. É evidente que eles serão modificados a partir de vários aspectos atinentes a cada processo de ensino-aprendizagem em si, como as variantes de cada prática motriz em desenvolvimento, dos conteúdos, da realidade encontrada, das concepções didático-pedagógicas do professor e, principalmente, dos objetivos estabelecidos para Educação Física. Compreende-se que, com inovações didático-metodológicas, será possível descontruir a desconfiança científica atrelada à área e superar o hegemônico caráter tecnicista dos processos de ensino-aprendizagem esportivos, na busca de uma Educação Física bem estruturada e, principalmente, com excelência científica naquilo que se propõe a fazer.

\section{REFERÊNCIAS}

ALMOND, Len. Rethinking Teaching Games for Understanding. Ágora, para la Educación Fisica y el Deporte, v. 17, n. 1, pp. 15-25, 2015.

BRASIL. Lei de Responsabilidade Fiscal do Esporte, nº 13.155, de 4 de agosto de 2015.

BOLONHINI, Sabine Zink; PAES, Roberto Rodrigues. A Proposta Pedagógica do Teaching Games for Understanding: Reflexões sobre a Iniciação Esportiva. Pensar a Prática, Goiânia, v. 12, n. 2, pp. 1-6, 2009.

BUNKER, David; THORPE, Rod. A Model for the Teaching of Games in Secondary Schools. Bulletin of Physical Education, Spring, v. 18, n. 1, 1982.

BUNKER, David; THORPE, Rod. The Curriculum Model. In: THORPE, R.; BUNKER, D.;

ALMOND, L. (ED.) Rethinking Games Teaching. Loughborough: University of Technology, Loughborough, pp. 7-10, 1986.

CLEMENTE, Filipe Manuel. Princípios Pedagógicos do Teaching Games for Understanding e da Pedagogia Não-Linear no Ensino da Educação Física. Movimento, Porto Alegre, v. 18, n. 02, pp. 315-335, abr/jun, 2012.

CLEMENTE, Filipe Manuel. Uma Visão Integrada do Modelo Teaching Games for Understanding: adequando os estilos de ensino e questionamento à realidade da educação física. Revista Brasileira de Ciência do Esporte, Florianópolis, v. 36, n. 2, pp. 587-601, abr/jun, 2014.

CÓSSIO-BOLAÑOS, Marco Antonio; PASCOAL, Eduardo Henrique Frazilli; PAES, Roberto Rodrigues; ARRUDA, Miguel de. Métodos de ensino nos Jogos Esportivos. Movimento \& Percepção, Espírito Santo do Pinhal, SP, v. 10, n. 15, jul/dez, pp. 264-273, 2009.

DEMO, Pedro. Metodologia Científica em Ciências Sociais. São Paulo: Atlas, 1995.

FAGUNDES, Felipe Menezes; RIBAS, João Francisco Magno; FRANCHI, Silvester; LANES, Bruno Minuzzi; OLIVEIRA, Raquel Valente de. Organização didática dos conteúdos da Educação Física a partir dos Domínios De Ação Motriz. In: VIII Salão Internacional de Ensino, Pesquisa e Extensão, 8, Uruguaiana, 2016. Anais eletrônicos... Uruguaiana: Universidade do Pampa. 
FOTIA, José. Voleibol, Lógica Interna e Iniciación. Acción Motriz, Las Palmas Del Gran Canaria. v. 10, pp. $76-83,2013$.

GARGANTA, Julio. Para uma Teoria dos Jogos Desportivos Colectivos. In: Graça, A. \& Oliveira, J. (Org.). O ensino dos jogos desportivos. v. 3, Ed. Porto: Universidade do Porto, pp. 11-26, 1998.

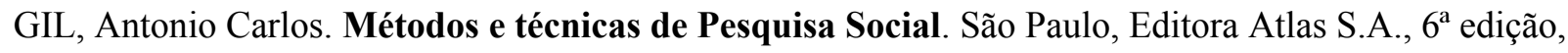
2008.

GRAÇA, Amândio; MESQUITA, Isabel. A investigação sobre os modelos de ensino dos Jogos Desportivos. Revista Portuguesa de Ciência do Desporto, v. 7, n. 3, pp. 401-421, 2007.

HERNÁNDEZ MORENO, José; RODRÍGUEZ RIBAS, Juan Pedro. La Praxiologia Motriz: fundamentos y aplicaciones. Barcelona - Espanha: INDE Publicaciones, $1^{\text {a }}$ ed, 2004.

HOLT, Nicholas, STREAN, William; BENGOECHEA, Enrique García. Expanding The Teaching Games For Understanding Model: New Avenues For Future Research And Practice. Journal of Teaching in Physical Education, v. 21, p. 162-176, 2002.

HOOPER, Tim. Teaching Games for Understanding: the importance of student emphasis over content emphasis. Journal of Physical Education, Recreation and Dance, v. 73, n. 7, 2002.

KIRK, David; MACPHAIL, Ann. Teaching Games For Understanding And Situated Learning: Rethinking The Bunker-Thorpe Model. Journal of Teaching in Physical Education, v. 21, pp. 177-192, 2002.

LAGARDERA, Francisco Otero; LAVEGA, Pere Burgués. Introducción A La Praxiología Motriz. Barcelona: Editorial Paidotribo, 2003.

PARLEBAS, Piere. Juegos, Deporte Y Sociedad: léxico de Praxiología Motriz. Barcelona: Paidotribo, 2001.

RIBAS, João Francisco Magno. (Org.) Praxiologia Motriz e Voleibol: elementos para o trabalho pedagógico. Ijuí: UNIJUÍ, 2014.

RICHARDSON, Roberto Jarry. Pesquisa social: métodos e técnicas. São Paulo: Atlas, $3^{\mathrm{a}}$ ed, 2012.

SALVADOR, Ângelo Domingos. Métodos E Técnicas De Pesquisa Bibliográfica. Porto Alegre: Sulina, 1986.

SÁNCHEZ-GÓMEZ, Roberto; DEVÍS-DEVÍS, José; NAVARRO-ADELANTADO, Vicente. El modelo Teaching Games for Understanding en el contexto internacional y español: una perspectiva histórica. Ágora: para la Educación Física y el deporte, v. 17, n. 3, pp. 197-213, 2014.

TAN, Clara Wee Keat; CHOW, Jia Yi.; DAVIDS, Keith. 'How Does TGFU Work?': Examining The Relationship Between Learning Design In TGFU And A Nonlinear Pedagogy. Physical. Education \& Sport Pedagogy, Abingdon, v.16, n. 4, 2011.

THORPE, Rod; BUNKER, David; ALMOND, Len. (Ed.) Rethinking games teaching. Loughborough: University of Technology, Loughborough, pp. 7-10, 1986. 


\section{NOTAS DE AUTOR}

\section{AGRADECIMENTOS}

Agradecemos aos colegas do Grupo de Estudos Praxiológicos - GEP Brasil pelas discussões que proporcionaram a realização desse estudo.

\section{CONTRIBUIÇÃO DE AUTORIA}

Concepção do manuscrito: F. M. Fagundes. J. F. M. Ribas.

Coleta de dados: Não se aplica.

Análise de dados: Não se aplica.

Discussão dos resultados: F. M. Fagundes. J. F. M. Ribas.

Produção do texto: F. M. Fagundes. J. F. M. Ribas.

Revisão e aprovação: F. M. Fagundes. J. F. M. Ribas.

\section{FINANCIAMENTO}

O presente trabalho foi realizado com apoio da Coordenação de Aperfeiçoamento de Pessoal de Nível Superior - Brasil (Capes) - Código de Financiamento 001.

CONSENTIMENTO DE USO DE IMAGEM - Não se aplica.

APROVAÇÃO DE COMITÊ DE ÉTICA EM PESQUISA - Não se aplica.

\section{CONFLITO DE INTERESSES}

Não há conflitos de interesses.

\section{LICENÇA DE USO}

Os autores cedem à Motrivivência - ISSN 2175-8042 os direitos exclusivos de primeira publicação, com o trabalho simultaneamente licenciado sob a Licença Creative Commons Attribution Non-Comercial ShareAlike (CC BY-NC SA) 4.0 International. Esta licença permite que terceiros remixem, adaptem e criem a partir do trabalho publicado, desde que para fins não comerciais, atribuindo o devido crédito de autoria e publicação inicial neste periódico desde que adotem a mesma licença, compartilhar igual. Os autores têm autorização para assumir contratos adicionais separadamente, para distribuição não exclusiva da versão do trabalho publicada neste periódico (ex.: publicar em repositório institucional, em site pessoal, publicar uma tradução, ou como capítulo de livro), com reconhecimento de autoria e publicação inicial neste periódico, desde que para fins não comerciais e compartilhar com a mesma licença.

\section{PUBLISHER}

Universidade Federal de Santa Catarina. Programa de Pós-Graduação em Educação Física. LaboMídia - Laboratório e Observatório da Mídia Esportiva. Publicado no Portal de Periódicos UFSC. As ideias expressadas neste artigo são de responsabilidade de seus autores, não representando, necessariamente, a opinião dos editores ou da universidade.

\section{EDITORES}

Mauricio Roberto da Silva, Giovani De Lorenzi Pires, Rogério Santos Pereira

\section{HISTÓRICO}

Recebido em: 13 de agosto de 2019.

Aprovado em: 28 de maio de 2020. 